\title{
Connecting rhetoric, reality and research: the need for evaluation of General Practitioners with Special Interests
}

In 2000 the NHS Plan for health services in England proposed the creation of a cadre of 1000 General Practitioners with Special Interests (GPwSIs) within four years [1]. The General Practice Airways Group (GPIAG) has been very proactive in the development and refinement of this GPwSI role for the care of patients with respiratory disease. The GPIAG, in consultation and collaboration with a range of other organisations, has formulated a framework of GPwSI core activities and competencies [2] and more recently detaited proposals for the accreditation of GPwSIs in Respiratory Medicine [3].

The rhetoric surrounding the introduction of GPwSls is laudable and inherently attractive. Who could challenge the intention to improve service delivery and patient care by the provision of new services, improved access to existing services, and promulgation of best practice? In addition to patient benefit there is also the potential for professional development. The GPwSI role creates opportunities for a portfolio career and allows a general practitioner greater flexibility to use expertise and specialist skills. Opportunities for professional development are to be welcomed since they may prevent isolation and burnout and improve self-esteem [4]—desirable outcomes at a time of low morale and increasing job dissatisfaction amongst general practitioners [5].

The support for the concept of a GPwSI is not universal or unlimited. McLandburgh Wilson said "Twixt the optimist and the pessimist, the difference is droll: the optimist sees the doughnut; the pessimist, the hole" [6] and some observers have viewed the advent of the GPwSI as more hole than doughnut! Concern has been expressed that the advent of GPwSls might change the very nature of General Practice, discouraging its holistic approach and fragmenting patient care [7]. Others have identified potential unwanted 'knock on' effects; for example, diverting capacity from core practice activities, and overloading the remaining members of the primary care team. Doubt has also been expressed about the ability of intermediate care clinics to reduce demand on secondary care services. It was in the early 1960's that Milton I Roemer first proposed the concept of supplyinduced demand, noting that if you create a hospital bed it will always be filled irrespective of the need [8]. Roemer's Rule has subsequently been found applicable beyond the hospital setting and would suggest that the provision of more respiratory consultations in the community will not translate into a reduction in demand for secondary care services.

The pessimism and doubts about GPwSls arise not so much from a dislike of the rhetoric but from recognition of the reality - that, yet again, there is the introduction of policy that lacks a robust evidence base. There has not been the opportunity to collect and collate the evidence from pilot GPwSI schemes before developing policy and introducing an evidence-based service. Some might argue that this linear relationship between evidence and policy is of limited application [9] but it is certainly essential to move beyond a 
framework for development based solely upon beliefs, ideologies, anecdotes and experience [10].

Presently there is strong political support and considerable professional enthusiasm for GpwSIs, and so the paucity of evidence for benefit is unlikely to hinder their introduction. But with any service development there is a honeymoon period, which is frequently followed by a period of challenging questions and competition for resources. To ensure the continuing growth of GPwSIs in respiratory medicine, consideration needs to be given now to the issues of evaluation and the generation of evidence of effectiveness and cost-effectiveness. Without this evidence it will be impossible to confirm or refute the optimistic expectations for GPwSIs and the pessimists' fear of lack of benefit and unexpected outcomes. Some preliminary ideas for evaluation of GPwSls in respiratory medicine have already been proposed [11]. Suggested clinical indices include: the percentage of patients who, having experienced an acute asthma episode, can be considered to be self-managing six months later, with improved self-confidence and self-dependence; and the percentage of those with stable respiratory conditions who use their medications and devices effectively. The different approaches to the economic component of an evaluation have been outlined in a recenteditorial in this journal [12].

When developing a new service, evaluation may be a low priority for both managers and GPwSIs. Constructing an evaluation framework de novo is demanding of time and expertise; a more realistic approach could be the collaborative development of a shared evaluation resource. The exact nature of this resource requires further consideration by its beneficiaries, but one might envisage the compilation of an 'evaluation tool box' for GpwSIs in respiratory medicine. Contained within this, for instance, could be: examples of evaluation objectives; protocols; outcome and output measures; and data collection forms. This approach would not only facilitate evaluation of individual GpwSIs, but the standardisation of data collection methods would enable meaningful compar- isons to be made between different models of service. The GPIAG, with its track record of successful collaboration with respiratory-interested organisations, is well placed to provide this link between rhetoric, reality and research.

\section{References}

[1] Department of Health. The NHS Plan: A plan for investment, a plan for reform. London: The Stationery Office Ltd; 2000.

[2] Report of a working party of the General Practice Airways Group and the Royal College of General Practitioners. General Practitioners with a special interest in respiratory medicine. Prim Care Resp J 2003;12:38-41.

[3] Gruffydd-Jones K. A proposal for the process of accreditation by portfolio for a GPwSI in respiratory medicine. Prim Care Resp J 2004; doi: 10.1016/j.pcrj.2004.09.004.

[4] Calvert G, Britten N. The United and Dental School of Guy's and St Thomas' Hospitals MSc in General Practice: Graduates' perspectives. Med Ed 1999;33:130-5.

[5] Kmietowicz Z. Quarter of GPs want to quit, BMA survey shows. BMJ 2001;323:887A.

[6] Wilson M. Optimist and Pessimist, quoted in Stevenson's Book of Quotations. 9th ed. London: Cassell; 1964.

[7] Gerada C, Wright N, Keen J. The general practitioner with a special interest: new opportunities or the end of the generalist practitioner? Br J Gen Pract 2002;52:796-8.

[8] Roemer MI. Bed supply and hospital utilities: a natural experiment. Hosiptals 1961;35:36-42.

[9] Black N. Evidence-based policy: proceed with care. BMJ 2001;323:275-9.

[10] Lomas J. Connecting research and policy. Isuma: Can J Policy Res 2000;1:140-4.

[11] Williams S, Ryan D, Price D, Langley C, Fletcher M, Everden P. General practitioners with a special clinical interest: a model for improving respiratory disease management. $\mathrm{Br} \mathrm{J}$ Gen Pract 2002;52:838-43.

[12] Kernick $D$. The economic perspective of respiratory general practitioners with a special interest (GPwSIs): proceed with caution. Prim Care Resp J 2003;12:108-9.

$$
\begin{array}{r}
\text { Helen Smith } \\
\text { Brighton and Sussex Medical School } \\
\text { Room 319, Mayfield House. Falmer } \\
\text { Brighton, BN1 9PH, UK } \\
\text { Tel.: +44 } 1273644192 \\
\text { E-mail address: h.e.smith@bsms.ac.uk }
\end{array}
$$

25 October 2004

Available online at www.sciencedirect.com science@direct 